\title{
ATITUDES COM RELAÇÃO À EDUCAÇÃO A DISTÂNCIA EM UMA UNIVERSIDADE
}

\author{
Andrea Valéria Steil \\ Ana Elisa Pillon ${ }^{\#}$ \\ Vinícius Medina Kern"
}

\begin{abstract}
RESUMO. Este artigo descreve os resultados de uma pesquisa exploratória que investigou as atitudes de alunos com relação à educação a distância. A população-alvo foi de 22 alunos matriculados em uma disciplina a distância do curso Ciência da Computaç ão de uma instituição de ensino superior do Sul do Brasil, oferecida no primeiro semestre de 2003. A pesquisa foi de natureza descritiva e aplicada, realizada sob uma perspectiva predominantemente quantitativa. Os resultados revelaram atitudes negativas dos alunos, especialmente nas categorias desempenho, flexibilidade e conveniência, preparação para a educação a distância, material didático e dinâmica de grupo na lista de discussão. Esses resultados indicam que o impacto positivo esperado da educação a distância pode não se efetivar quando a instituição desconsidera tanto a complexidade do processo educacional a distância quanto as variáveis envolvidas no processo de adoção e aceitação de inovações educacionais pelos alunos.
\end{abstract}

Palavras-chave: atitudes, educação a distância, inovações educacionais.

\section{ATTITUDES TOWARDS COLLEGE EDUCATION AT A DISTANCE}

\begin{abstract}
The present article describes the results of an exploratory research in which the students' attitudes regarding education at the distance was investigated. The subjects of the study were 22 students enrolled in a discipline at the distance in the Computer Science undergraduate course. The course was offered in the first semester of 2003 in a college institution located in the South of Brazil. The research was of descriptive and applied nature, accomplished under a predominantly quantitative perspective. The results revealed the students' negative attitudes, especially towards the categories of performance, flexibility and convenience, preparation to the education at the distance, instructor-generated learning material, and group dynamics in the discussion list. These results suggest that the expected positive impact of the education at the distance may not be accomplished when the educational institution does not take into consideration the complexity of the process and the variables involved in the process of adoption and acceptance of educational innovations by the students.
\end{abstract}

Key words: Attitude, education at the distance, educational innovations.

Há crescente interesse na compreensão das atitudes de estudantes e de professores quanto à adoção de inovações educacionais (Berge, 2002; Evans, 1994; Martins, Steil \& Todesco, 2004; McGorry, 2002; Ocker, 2001; Ponzurick, France \& Logar, 2000; Waugh, 2002). Este aspecto está relacionado com o crescente número de alunos e de cursos de graduação a distância, fenômeno observado em diferentes países. Por exemplo, nos Estados Unidos, no biênio 2000-2001, 56\% de todas as instituições de ensino superior ofereciam cursos de graduação a distância. O número de matrículas cresceu, nos cursos de graduação e de pós-graduação, de 1,7 milhão para 3,1 milhões no mesmo período (U.S. Department of Education, 2004). No
Brasil o número absoluto de cursos e de alunos é menor, mas não menos significativo, principalmente considerandose as taxas de crescimento da educação a distância no ensino superior. O último censo da Educação Superior (Ministério da Educação, 2003) revelou um crescimento de $13 \%$ da educação a distância nas instituições brasileiras, de 2002 a 2003, passando de 46 para 52 os cursos de graduação. No mesmo período o número de alunos matriculados nestes cursos foi de 50.000 .

Não há estudos que comprovem que a maior disseminação da educação a distância em um contexto corresponda a uma atitude mais positiva ou mais negativa com relação a esta modalidade educacional.

\footnotetext{
* Doutora, coordenadora do Laboratório de Educação Virtual - LEVi, Instituto Virtual de Estudos Avançados - VIAS.

\# Graduanda em Psicologia - Univali, CE Biguaçu.

ף Doutor, docente da Univali/CE São José, Pesquisador da UFSC/PPG Engenharia e Gestão do Conhecimento, Diretor de Projetos e Pesquisa do Instituto Stela.
} 
Entretanto, em um estudo de Inman, Kerwin e Mayes (1999), com 334 estudantes e representantes de onze instituições de ensino superior nos Estados Unidos, identificou-se que um dos fatores que contribuem para a pequena taxa da adoção da educação a distância por algumas instituições de ensino superior pode estar relacionado com a existência de atitudes negativas quanto a essa inovação educacional.

Um fator que influencia as atitudes é o papel do professor e do aluno na educação a distância. Diferente do papel tradicional, desafia os esquemas de representação de alunos e de professores. Os esquemas são organizações cognitivas que representam o conhecimento sobre um conceito desenvolvido pela experiência passada e modelam a forma pela qual novas informações e situações são organizadas (Fiske \& Taylor, 1984). No caso em estudo, o esquema representa a relação educacional formal tradicional/prototípica e conduz o indivíduo a comparar e a julgar suas experiências educacionais com relação a esse esquema.

O esquema estabelecido com relação à situação de ensino formal tradicional baseia-se na presença dos professores e dos alunos em um mesmo espaço e tempo. Como consequiência, assume-se que existe a necessidade de manutenção dessa configuração para que a aprendizagem ocorra (Alexander, 2001; Inman \& cols., 1999). Em função disso, as configurações educacionais que diferem desse esquema podem ser vistas com apreensão e ceticismo.

No escopo deste artigo utiliza-se a abordagem de Aretio (2001) sobre a educação a distância. O referido autor identifica as seguintes características necessárias e suficientes para considerar um curso, programa ou instituição como de educação a distância: a quase permanente separação do professor ou formador e do aluno ou participante no espaço e no tempo; o estudo independente, em que o aluno controla o tempo e o espaço, e determinados ritmos de estudo. Segundo Aretio (2001), essas características podem ser complementares - ainda que não seja necessário - às possibilidades de interação em encontros presenciais ou eletrônicos que oferecem oportunidades para a socialização e a aprendizagem colaborativa.

A busca por uma conceitualização precisa de educação a distância tem ocorrido por mais de duas décadas sem o desenvolvimento de um consenso entre os pesquisadores da área (Lowe \& Gunawardena, 2005). Apesar disso, o posicionamento mais aceito atualmente é o de que o uso de tecnologias da informação e da comunicação no contexto educacional tem possibilitado mais a convergência entre os modelos de educação tradicional e os modelos denominados de educação a distância do que o inverso (Commonwealth of Learning, 2003).
Este artigo investiga as atitudes de alunos de uma disciplina a distância em uma instituição de ensino superior do Sul do Brasil. As primeiras seções tratam da definição e das funções das atitudes, bem como dos resultados de estudos que identificaram as atitudes de alunos diante de inovações educacionais. Logo após, a metodologia apresenta os participantes da pesquisa e os procedimentos utilizados. Os resultados são relatados em seguida. Por fim, são discutidos os resultados e são apresentadas as conclusões.

\section{DEFINIÇÃO E FUNÇÕES DAS ATITUDES}

A atitude é considerada um dos principais construtos das ciências comportamentais e sociais. Há consenso sobre a compreensão das atitudes como disposições mentais para avaliar um objeto psicológico, expressas em dimensões de atributos, como bom/mau, agradável/desagradável, etc. (Ajzen, 2001; Wood, 2000). Há indícios crescentes de que a avaliação dirigida a um objeto surge imediatamente, sem esforço consciente. As avaliações são ativadas automaticamente mesmo quando os julgamentos avaliativos não são esperados ou solicitados (Bargh \& Chartrand, 1999).

As atitudes são influenciadas simultaneamente pela cognição e pelo afeto. O grau de influência desses dois elementos difere entre os indivíduos na determinação das atitudes dirigidas a diferentes objetos; porém, quando a cognição e os sentimentos com relação a um objeto possuem valências opostas, a influência dos sentimentos tende a predominar (Lavine, Thomsen, Zanna \& Borgida, 1998). De forma complementar, a informação negativa tem impacto maior do que a positiva no desenvolvimento das atitudes. Há experimentos que indicam que existe maior atividade cognitiva e melhor memória para as palavras negativas do que para as positivas (Ajzen, 2001).

As funções das atitudes estão relacionadas ao aumento da adaptação do indivíduo ao ambiente e podem ser assim categorizadas: a) de expressão de valores; b) de conhecimento; c) de defesa egóica; d) de ajustamento social; e d) de utilização (ou utilitária). Em consonância com essas funções, as atitudes possuem um efeito tendencioso sobre os julgamentos e a memória humana. Os indivíduos tendem a favorecer a aceitação de materiais e idéias consistentes com a atitude existente e a não levar em consideração o que a contradiz (Ajzen, 2001; Havice, 1999).

\section{ATITUDES COM RELAÇÃO À EDUCAÇÃO A DISTÂNCIA}

As atitudes dos estudantes com relação à educação a distância são indicadores tão importantes 
quanto seu desempenho na identificação da eficácia dos cursos e dos programas realizados a distância (Valenta, Therriault, Dieter \& Mrtek, 2001). Em função disso, Ocker (2001) sugere a necessidade de se explorarem as atitudes e as opiniões dos alunos quando da implementação de tecnologias educacionais. De acordo com Havice (1999), as atitudes influenciam a motivação para aprender e ajudam a delinear as ações humanas, incluindo a aceitação de mensagens educacionais.

A literatura relacionada às atitudes dos estudantes ante seus cursos sugere que a mídia utilizada no processo educacional não tem influência nas atitudes (Havice, 1999). Apesar desse indício, os resultados das pesquisas sobre os efeitos da educação a distância nas atitudes dos estudantes diante de diferentes cursos não são conclusivos (McGreal, 1994).

Por exemplo, Havice (1999) investigou se havia ou não diferença nas atitudes de estudantes universitários com relação a um sistema integrado de mídia, quando comparado com o método tradicional de palestras. Os resultados indicaram que não houve diferença significativa nas atitudes em direção ao curso nos grupos experimental e de controle, o que reforça a tese de que não há influência das mídias utilizadas nas atitudes dos alunos.

Akerlind e Trevitt (1999) pesquisaram os fatores que induzem os estudantes a resistir à aprendizagem mediada por tecnologia. Concluíram que, em termos gerais, quanto mais satisfeitos os estudantes estão com as suas experiências de aprendizagem tradicionais, sem o uso de tecnologias, menos estarão preparados para aceitar métodos de aprendizagens não familiares. Para esses estudantes, a imposição externa do uso de métodos tecnológicos, quando os estudantes possuem pouco conhecimento sobre o tema, geralmente produz sentimentos de desconforto e de ansiedade, de perda de controle pessoal e de medo de: a) aprender menos e b) não saber quais elementos do tópico em estudo devem priorizar.

Outro estudo sobre as atitudes em face da utilização de sistemas tecnológicos de autoaprendizagem, realizado com alunos de graduação em Marketing, indicou que as atitudes dependem da motivação individual para o alcance de sucesso na profissão e/ou da curiosidade do estudante e do seu envolvimento com o curso (Bennet \& Kottasz, 2001).

Nesta seção foram descritos os principais estudos que formaram a base teórico-empírica para o delineamento desta pesquisa, cujos resultados são descritos nas próximas seções.

\section{MÉTODO}

Esta pesquisa investigou as atitudes dos alunos com relação à educação a distância. A populaçãoalvo foram os alunos matriculados $(n=22)$ em uma disciplina a distância de uma instituição de ensino superior do Sul do Brasil, oferecida no primeiro semestre de 2003. Essa é uma disciplina obrigatória, com quatro créditos (60 horas/aula). Destaca-se que esse foi o primeiro semestre em que a disciplina foi oferecida a distância, sem que os alunos tivessem a possibilidade de realizá-la na modalidade presencial.

A disciplina teve 16 aulas de quatro horas/aula, incluindo o dia do exame final. Da carga horária total da disciplina, o equivalente a nove aulas (36 horas/aula), foi realizado a distância $(56,25 \%$ da carga horária total). As aulas a distância envolveram a leitura do material didático (disponível na forma de arquivos digitais para download), a realização de exercícios e a interação com o professor e com os colegas por meio de grupos de discussão on-line e chats. Os grupos de discussão deveriam ser freqüentados semanalmente pelos alunos e pelo professor, com uma data predeterminada de acesso por parte do professor. A participação nos chats seria obrigatória e levada em consideração para a avaliação do aluno.

A pesquisa foi exploratória, de natureza descritiva e aplicada. O problema de pesquisa foi analisado sob uma perspectiva predominantemente quantitativa. Foram coletados dados primários por meio da aplicação de um questionário a todos os alunos matriculados disciplina, em maio de 2003, após cerca de dois meses do início da disciplina.

As assertivas foram desenvolvidas a partir da análise de diferentes instrumentos de aferição de atitudes e, mais particularmente, do instrumento para verificar a atitude de alunos com relação à educação a distância desenvolvido por Hong, Lai e Holton (2003). Antes de se aplicarem os questionários, foi adotado o procedimento de validação semântica.

A primeira parte do questionário investigou o perfil dos alunos; a segunda, as atitudes desses com relação a diferentes categorias de análise: desempenho, professor, flexibilidade e conveniência, experiência positiva, preparação para a educação a distância, ambiente de aprendizagem, material didático e dinâmica do grupo na lista de discussão. Com relação às escalas de graduação para resposta da segunda parte do questionário, foram apresentadas as assertivas com cinco opções 
de resposta: (1) discordo plenamente; (2) discordo; (3) neutro; (4) concordo; e (5) concordo plenamente. Foi garantida a confidencialidade das respostas, uma vez que os respondentes não se identificaram no questionário, sendo este entregue e recolhido diretamente pela segunda autora desta pesquisa.

Quanto às limitações, ressalta-se que este estudo é de natureza exploratória e, como tal, não pode ser generalizado para outros ambientes e populações de alunos. Além deste aspecto, o instrumento de levantamento de dados, apesar de ter sido elaborado a partir de uma escala consolidada (Hong \& cols., 2003), precisa de validação estatística, de modo que se tenha certeza de que ele mede e operacionaliza efetivamente os construtos sob investigação.

\section{DISCUSSÃO DOS RESULTADOS}

Os 22 questionários foram entregues, preenchidos e devolvidos durante uma das aulas presenciais da disciplina, o que garantiu a participação da populaçãoalvo. Com relação ao perfil dos sujeitos da pesquisa, $19(86,36 \%)$ eram do sexo masculino. A faixa etária predominante foi entre 20 e 25 anos, com 18 sujeitos $(81,81 \%)$; seguida da faixa entre 26 e 30 anos, com três sujeitos $(13,63 \%)$. Uma pessoa não identificou a sua idade. Nenhum dos sujeitos havia participado de algum curso ou disciplina a distância.

Nas tabelas a seguir são apresentadas as médias das respostas por assertiva, os coeficientes de variação e os conseqüentes percentuais de homogeneidade nas respostas. A partir da escala utilizada, as médias mais próximas de cinco referem-se à concordância máxima com a assertiva, e as médias próximas de um dizem respeito à não-concordância com a assertiva.

Para se analisar o grau de homogeneidade nas respostas, utilizou-se o coeficiente de variação $(\mathrm{CV})$, que é determinado pela razão entre o desvio-padrão e a média. Optou-se pela utilização do coeficiente de variação porque ele expressa a dispersão das respostas em termos relativos, tirando a influência da ordem de grandeza da variável. Neste estudo, o percentual de homogeneidade nas respostas oscilou grandemente e variou de $8 \%$ até $89 \%$.

Os resultados apresentados nas Tabelas 1 a 9 indicam que os alunos pesquisados possuem uma atitude negativa diante da maioria das categorias investigadas. Com relação à categoria desempenho, os alunos acreditam que a disciplina não os têm auxiliado na aprendizagem do conteúdo (média 1,73 ) e que não precisam estudar mais para a disciplina a distância do que teriam caso ela fosse presencial (média 2,05). A única assertiva com respostas próximas do ponto neutro diz respeito à nota que os alunos esperam obter na disciplina (média 2,59). Observa-se também um baixo grau de concordância entre as respostas (Tabela 1).

Tabela 1. Atitudes dos alunos pesquisados com relação à categoria desempenho

\begin{tabular}{llll}
\hline Assertivas & Média & CV Conc. \\
\hline $\begin{array}{l}\text { 1. Sinto que o curso na modalidade a distância } \\
\text { tem me ajudado a aprender [o nome da } \\
\text { disciplina]. }\end{array}$ & 1,73 & 0,41 & $59 \%$ \\
$\begin{array}{l}\text { 2. A nota que eu espero tirar nesta disciplina a } \\
\text { distância é similar à que eu tiraria caso a } \\
\text { disciplina fosse presencial. }\end{array}$ & 2,59 & 0,51 & $49 \%$ \\
$\begin{array}{l}\text { 3. Eu preciso estudar mais para esta disciplina a } \\
\text { distância do que eu tenho que estudar para as } \\
\text { disciplinas presenciais. }\end{array}$ & 2,05 & $0,51 \quad 49 \%$ \\
\hline
\end{tabular}

A atitude dos alunos com relação ao seu desempenho está em discordância com outros estudos, que indicam a não-existência de diferenças significativas entre os resultados de aprendizagem de alunos matriculados em cursos presenciais e os resultados de cursos a distância (Hong \& cols., 2003; Layton, 1999). As atitudes negativas dos alunos também não se refletiram no desempenho real destes na disciplina sob análise. Conforme a Tabela 2, não houve diferença significativa no desempenho dos alunos matriculados nessa disciplina a distância quando comparado com o desempenho dos alunos matriculados na mesma disciplina (com o mesmo professor) presencial. Em uma série histórica de seis anos, tanto o percentual de aprovação quanto a média final dos alunos pouco variaram.

Tabela 2. Percentual de aprovação e média final da disciplina sob análise, no período de 1998 a 2003

\begin{tabular}{lcc}
\hline Semestre & Aprovação $(\%)$ & Média final \\
\hline 2003 I - a distância & 92,3 & 7,79 \\
2002 II - presencial & 87,5 & 7,85 \\
2002 I - presencial & 88,8 & 8,19 \\
2001 II - presencial & 77,7 & 7,89 \\
2001 I - presencial & 66,6 & 6,64 \\
2000 II - presencial & 100 & 7,50 \\
2000 I - presencial & 92,3 & 6,62 \\
1999 II - presencial & 94,44 & 7,23 \\
1999 I - presencial & 81,81 & 7,44 \\
1998 II - presencial & 92,59 & 7,76 \\
\hline
\end{tabular}

Fonte: Secretaria Acadêmica da Instituição de Ensino Superior.

O desempenho esperado pode afetar a percepção de qualidade de um curso a distância e, 
conseqüentemente, a atitude dos alunos. Inman e cols. (1999), em uma pesquisa que investigou a percepção de qualidade de 334 alunos de cursos a distância de 11 instituições de ensino superior nos Estados Unidos, verificaram que a percepção dos alunos com relação ao desempenho respondeu por $4 \%$ da variância da qualidade percebida do curso.

No que tange ao desempenho do professor, a atitude dos alunos manteve-se próxima da neutralidade quanto à promoção de um ambiente de aprendizagem agradável e estimulante (média 3,09). Os alunos demonstraram sua concordância com a presteza do professor para responder às questões encaminhadas por e-mail ou pelo ambiente de aprendizagem (média 4,23). Neste aspecto houve alto grau de homogeneidade nas respostas $(82 \%)$ (Tabela 3).

Tabela 3. Atitudes dos alunos pesquisados com relação à categoria professor

\begin{tabular}{lllll}
\hline Assertivas & Média & CV Conc. \\
\hline $\begin{array}{l}\text { 4. De maneira geral, o professor tem auxiliado } \\
\text { efetivamente o grupo a aprender [o nome da } \\
\text { disciplina]. }\end{array}$ & 1,36 & 0,70 & $30 \%$ \\
$\begin{array}{l}\text { 5. Nessa disciplina a distância tenho recebido } \\
\text { mais atenção individual do professor do que nas } \\
\text { disciplinas presenciais. }\end{array}$ & 2,09 & 0,53 & $47 \%$ \\
$\begin{array}{l}\text { 6. O formato da disciplina (a distância) tem } \\
\text { facilitado a minha interação com o professor. }\end{array}$ & 2,32 & 0,39 & $61 \%$ \\
$\begin{array}{l}\text { 7. O professor tem encorajado a aprendizagem dos } \\
\text { alunos por meio de questionamentos, desafios e } \\
\text { críticas. }\end{array}$ & 2,18 & 0,48 & $52 \%$ \\
$\begin{array}{l}\text { 8. O professor tem promovido um ambiente de } \\
\text { aprendizagem agradável e estimulante. }\end{array}$ & 3,09 & 0,39 & $61 \%$ \\
$\begin{array}{l}\text { 9. O professor tem respondido às questões } \\
\text { encaminhadas por e-mail ou pelo ambiente de } \\
\text { aprendizagem on-line em, no máximo, 24 horas. }\end{array}$ & 4,23 & 0,18 & $82 \%$ \\
\hline
\end{tabular}

Os resultados das demais assertivas revelam uma atitude negativa dos alunos com relação ao desempenho do professor. Este, de acordo com os alunos, não os auxiliou no processo de aprendizagem (média 1,36), dispensou menos atenção aos alunos do que dispensaria para os alunos em uma disciplina presencial (média 2,09) e não encorajou a aprendizagem por meio de questionamentos, desafios e críticas (média 2,18) (Tabela 3).

Esses resultados novamente contradizem outros estudos, que indicam que os alunos valorizam o feedback rápido e constante com relação ao seu desempenho e à clarificação das expectativas por parte do professor (Alexander, 2001). Especificamente quanto às atitudes em direção à educação a distância, Valenta \& cols. (2001) demonstram que podem ser grandemente afetadas por meio do aumento e da facilitação da interação entre alunos e professores Os resultados dessa categoria remetem a um paradoxo, porque os alunos reconhecem que o professor dá retorno aos seus questionamentos em até 24 horas, mas não interpretam esse retorno como um auxílio para a sua aprendizagem ou como uma atenção individual. Novas pesquisas precisam ser realizadas para que se compreenda a natureza da atenção esperada dos professores, pelos alunos, em cursos a distância.

$\mathrm{Na}$ categoria flexibilidade e conveniência, os resultados indicam uma atitude negativa dos alunos pesquisados (Tabela 4), outra vez em dissonância com a literatura internacional, que aponta para um consenso de que a educação a distância possibilita aos alunos terem maior controle sobre o seu processo de aprendizagem, na medida em que podem escolher o local, a hora e o ritmo de seu estudo (Baer, 2000; Hong \& cols., 2003; Weller, 2000).

Tabela 4. Atitudes dos alunos pesquisados com relação à categoria flexibilidade e conveniência

\begin{tabular}{|c|c|c|c|}
\hline Assertivas & Média & $\mathrm{CV}$ & $\begin{array}{c}\text { Conc } \\
.\end{array}$ \\
\hline $\begin{array}{l}\text { 10. O fato de a disciplina ser a distância faz } \\
\text { com que eu possa aprender em meu } \\
\text { próprio ritmo. }\end{array}$ & 2,50 & 0,53 & $47 \%$ \\
\hline $\begin{array}{l}\text { 11. A disciplina na modalidade a distância } \\
\text { está sendo conveniente para mim, pois } \\
\text { aumenta a minha flexibilidade. }\end{array}$ & 1,73 & 0,69 & $31 \%$ \\
\hline
\end{tabular}

Os resultados da próxima categoria, experiência positiva (Tabela 5), demonstraram uma atitude negativa quanto à sensação de que a disciplina manteve as oportunidades para conhecer os colegas de sala (média 3,91) e a necessidade de maior iniciativa e atitude mais ativa para realizar a disciplina (média 4,55). Os alunos não se matriculariam novamente em uma disciplina a distância na instituição em que estudam (média 1,55), e também não recomendariam a nenhum colega a realização de uma disciplina a distância na instituição (média 2,05). Em consonância com estes resultados, um estudo teórico-empírico (Long, Tricker, Rangecroft \& Gilroy, 2000) verificou que alunos que realizavam uma disciplina de graduação a distância explicitaram a existência de um hiato significativo, de valência negativa, entre o que esperavam de um curso a distância e o que efetivamente vivenciaram. 
Tabela 5. Atitudes dos alunos pesquisados com relação à categoria experiência positiva

\begin{tabular}{|c|c|c|c|}
\hline Assertivas & Média & CV & Conc. \\
\hline $\begin{array}{l}\text { 12. Realizar essa disciplina a distância tem diminuído as } \\
\text { oportunidades para eu conhecer melhor os meus } \\
\text { colegas de sala. }\end{array}$ & 3,91 & 0,55 & $45 \%$ \\
\hline $\begin{array}{l}\text { 13. Realizar uma disciplina a distância requer maior } \\
\text { iniciativa e aprendizagem ativa por parte do aluno. }\end{array}$ & 4,55 & 0,11 & $89 \%$ \\
\hline $\begin{array}{l}\text { 14. Eu recomendaria para os meus colegas realizarem } \\
\text { alguma disciplina a distância na [nome da } \\
\text { instituição]. }\end{array}$ & 2,05 & 0,82 & $18 \%$ \\
\hline $\begin{array}{l}\text { 15. Eu me matricularia em outra disciplina a distância da } \\
\text { [nome da instituição]. }\end{array}$ & 1,55 & 0,72 & $28 \%$ \\
\hline
\end{tabular}

Uma hipótese que pode ser levantada para compreender a atitude negativa com relação à experiência de cursar uma disciplina a distância está relacionada com o pequeno grau de presença social, identificado na categoria professor. A presença social é um preditor significativo da satisfação de alunos com a educação a distância (Gunawardena \& Zittle 1997) e diz respeito aos construtos da distância psicológica aos sentimentos de intimidade e ao grau com que uma pessoa sente acessar a inteligência, as intenções e as impressões sensoriais de outra pessoa. A percepção, por parte dos sujeitos desta pesquisa, de pouca atenção individual, auxílio na aprendizagem e questionamentos por parte do professor se reflete na percepção de pouca presença social, o que influi no desenvolvimento de uma insatisfação com o curso. Para a confirmação ou rejeição dessa hipótese, novos estudos precisam ser realizados, principalmente porque os resultados das pesquisas nessa área não são conclusivos. Por exemplo, um estudo realizado por Fulford e Zhang (1993) verificou que a satisfação de alunos com cursos a distância não resultou da participação ativa por parte dos alunos, mas foi decorrente da percepção de que a interação efetivamente ocorria.

Os resultados da categoria preparação para a educação a distância indicam a insatisfação dos alunos com relação às informações recebidas sobre a disciplina (média 1,45). $\mathrm{O}$ elevado grau de dissenso das respostas pode resultar da desinformação e da ansiedade com relação ao processo de ensino/aprendizagem a distância (Tabela 6).

Tabela 6. Atitudes dos alunos pesquisados com relação à categoria preparação para a educação a distância

\begin{tabular}{|c|c|c|}
\hline Assertiva & Média & CV Conc. \\
\hline $\begin{array}{l}\text { 16. Eu recebi as informações necessárias, em } \\
\text { quantidade suficiente, antes de iniciar a } \\
\text { disciplina, sobre o que é educação a } \\
\text { distância, sobre o papel do professor e do } \\
\text { aluno nessa modalidade de ensino. }\end{array}$ & 1,45 & $0,92 \quad 08 \%$ \\
\hline
\end{tabular}

Essa ansiedade pode estar relacionada a uma atitude de manutenção do esquema representativo da sala de aula tradicional. Os alunos podem recear ser obrigados a se adequar a uma realidade na qual precisarão de mais motivação e disciplina (Ascough, 2002) ou manter uma atitude de que a configuração tradicional de ensino/aprendizagem precisa ser mantida para que a aprendizagem ocorra (Alexander, 2001; Inman \& cols., 1999).

Há, também, um dado de realidade que pode ter influenciado os resultados desta e das demais categorias sob investigação. Os alunos declararam haver sido informados sobre o caráter a distância apenas no primeiro dia de aula. Esse fato pode ter gerado um sentimento de quebra de contrato psicológico, de forma a desenvolver uma atitude negativa com relação à instituição e à disciplina. O contrato psicológico configura-se em um conjunto de expectativas acerca das obrigações recíprocas entre o indivíduo e a instituição da qual este faz parte (Schein, 1965). Ele também pode ser compreendido como as crenças de um indivíduo sobre as obrigações recíprocas entre si e a instituição. Essas obrigações são baseadas em expectativas e promessas percebidas, as quais não são, necessariamente, reconhecidas pelos dirigentes desta organização (Morrison \& Robinson, 1997).

A categoria ambiente de aprendizagem contém uma assertiva relacionada à usabilidade do ambiente de aprendizagem, uma assertiva relacionada à flexibilidade de acesso ao ambiente e assertivas referentes ao comportamento do aluno diante do ambiente de aprendizagem on-line. Com relação a esses aspectos, os alunos reconhecem o fato de poderem acessar o curso de qualquer lugar com conexão à internet (média 3,8), embora considerem que o ambiente de aprendizagem online não seja estável nem de fácil utilização (média 1,27) (Tabela 7). Aglutinaram-se dois indicadores referentes ao ambiente de aprendizagem on-line, estável e de fácil utilização, na medida em que ambos referem-se ao conceito mais amplo de usabilidade, o qual diz respeito à capacidade que um sistema interativo oferece a seu usuário, em um determinado contexto de operação, para a realização de tarefas de maneira eficaz, eficiente e agradável (International Standards Organisation, 1999). 
Tabela 7. Atitudes dos alunos pesquisados com relação à categoria ambiente de aprendizagem

\begin{tabular}{lllll}
\hline Assertivas & Média & CV Conc. \\
\hline $\begin{array}{l}\text { 17. O ambiente de aprendizagem on-line é estável } \\
\text { e de fácil utilização. }\end{array}$ & 1,27 & 0,90 & $10 \%$ \\
$\begin{array}{l}\text { 18. Eu posso acessar o curso de qualquer lugar } \\
\text { onde tenha um computador e acesso à internet. }\end{array}$ & 3,82 & 0,32 & $68 \%$ \\
$\begin{array}{l}\text { 19. Os chats têm auxiliado a minha aprendizagem. } \\
\text { 20. Eu sou pontual nos chats e estou preparado }\end{array}$ & 1,41 & 0,42 & $58 \%$ \\
$\begin{array}{l}\text { para aproveitar a discussão no chat. } \\
\text { 21. O ambiente de aprendizagem on-line facilita a } \\
\text { integração com o professor e com os colegas. }\end{array}$ & 2,27 & 0,58 & $42 \%$ \\
$\begin{array}{l}\text { 22. O ambiente de aprendizagem on-line facilita a } \\
\text { disseminação e o acesso ao material didático. }\end{array}$ & 2,95 & 0,40 & $60 \%$ \\
\hline
\end{tabular}

As assertivas 20, 21 e 22 analisam simultaneamente uma dupla de aspectos. Embora se tenha clareza de que os resultados poderiam ser mais pontuais se as duplas de aspectos fossem decompostas (ou seja, uma assertiva por aspecto analisado), optouse por se manter a lógica utilizada por Hong e cols. (2003) de utilização das duplas de aspectos.

O ambiente de aprendizagem utilizado também não é considerado um facilitador da integração com professores e colegas (média 2,27), nem de disseminação e acesso ao material didático (média 2,95). A atitude diante dos chats foi negativa, tanto no que diz respeito ao seu papel no auxílio da aprendizagem (média 1,41) quanto na preparação dos alunos para aproveitar as discussões (média 2,14).

Tabela 8. Atitudes dos alunos pesquisados com relação à categoria material didático

\begin{tabular}{llll}
\hline Assertivas & Média & CV Conc. \\
\hline $\begin{array}{l}\text { 23. O material didático on-line está adequadamente } \\
\text { formatado para o estudo a distância. }\end{array}$ & 2,73 & 0,48 & $52 \%$ \\
$\begin{array}{l}\text { 24. O uso dos recursos a distância da disciplina } \\
\text { (material } \text { on-line, material impresso, lista de }\end{array}$ & & & \\
$\begin{array}{l}\text { discussão, chats, etc.) tem auxiliado na } \\
\text { minha compreensão da disciplina. }\end{array}$ & 1,95 & 0,48 & $52 \%$ \\
\hline
\end{tabular}

No primeiro dia de aula os alunos receberam orientações sobre a educação a distância e suas características, incluindo o papel mediador do material didático, por parte do núcleo de educação a distância da instituição de ensino superior. A partir destas informações, os alunos investigados demonstraram atitude negativa com relação à formatação do material didático utilizado na disciplina para a educação a distância (assertiva 23 = média 2,73). Consideraram, também, que os recursos oferecidos na disciplina não auxiliaram na compreensão do assunto (assertiva $24=$ média 1,95) (Tabela 8).
Com relação ao material didático, muitos pesquisadores já alertaram para o fato de que várias tentativas do uso da tecnologia da informação no ensino resumiram-se à inserção de material educacional tradicional no ambiente de aprendizagem, sem qualquer adaptação para o seu uso na educação a distância (Griffiths, Ashoweth, Ward \& Mardsen, 1999; Evans, Gibbons, Shah \& Griffin, 2004). Dois estudos realizados por Evans e cols. (2004) detectaram que qualquer melhora no desempenho ou na avaliação subjetiva da efetividade de um curso a distância é grandemente influenciada pelos materiais educacionais utilizados.

De forma complementar, em uma pesquisa com 334 alunos de graduação que realizaram um curso a distância, Inman e cols. (1999) investigaram: 1) a satisfação com relação à qualidade do processo de ensino/aprendizagem; 2) a qualidade geral do curso; e 3) a quantidade da aprendizagem decorrente do curso. Com relação ao primeiro aspecto, três variáveis foram responsáveis por $69 \%$ da variância nas respostas. A qualidade do material didático produzido pelo professor respondeu por $55 \%$ da variância na avaliação deste. $\mathrm{O}$ segundo fator mais importante foi a qualidade das atividades presenciais, responsável por $9 \%$ da variância na avaliação do professor. O terceiro fator mais importante foi a disponibilidade percebida do professor, responsável por $5 \%$ da variância de sua avaliação.

Com relação ao segundo aspecto, duas variáveis responderam por $59 \%$ da variância nas avaliações dos estudantes com relação à qualidade do curso: os materiais do curso (55\% da variância) e a percepção dos alunos com relação a quanto aprenderam (4\% da variância). Com relação ao terceiro aspecto, três variáveis foram responsáveis por $48 \%$ da variância na avaliação dos alunos com relação a quanto perceberam ter aprendido no curso. A variável mais preditiva foi a que se refere aos materiais produzidos pelos professores (33\% da variância da quantidade do que foi aprendido). $\mathrm{O}$ segundo fator está relacionado com os materiais do curso (outras fontes de informação), responsável por $7 \%$ da variação na quantidade do que se aprendeu. A terceira variável foi a quantidade de trabalho que os alunos tiveram de realizar, quando comparada com outros cursos (8\% da variância da quantidade aprendida). Quanto mais trabalho foi requerido, mais os alunos sentiram ter aprendido (Inman \& cols. 1999).

Uma vez que a lista de discussão foi utilizada como um recurso didático na disciplina, nesta 
pesquisa quatro assertivas foram desenvolvidas para analisá-la (Tabela 9).

Tabela 9. Atitudes dos alunos pesquisados com relação à categoria dinâmica do grupo na lista de discussão.

\begin{tabular}{lllll}
\hline Assertivas & $\begin{array}{c}\text { Médi } \\
\text { a }\end{array}$ & & \\
\hline $\begin{array}{l}\text { 25. O formato da disciplina tem facilitado a minha } \\
\text { interação com os meus colegas de sala. }\end{array}$ & 2,14 & 0,44 & $56 \%$ \\
$\begin{array}{l}\text { 26. A discussão do grupo na lista tem auxiliado a } \\
\text { minha compreensão da disciplina. }\end{array}$ & 2,27 & 0,53 & $47 \%$ \\
$\begin{array}{l}\text { 27. Eu contribuo regularmente nas discussões da } \\
\text { lista. }\end{array}$ & 2,95 & 0,48 & $52 \%$ \\
$\begin{array}{l}\text { 28. Eu aprendi com outros alunos durante as } \\
\text { discussões na lista. }\end{array}$ & 1,00 & 1,47 & $47 \%$ \\
\hline
\end{tabular}

$\mathrm{Na}$ visão dos alunos, a lista de discussão não contribuiu para a compreensão da disciplina (média 2,27) e para a interação com os colegas (média 2,14). A participação dos colegas na lista também não foi vista como um insumo para a aprendizagem (média 1,00). Os próprios alunos admitem que não contribuem regularmente nas discussões da lista (média 2,95).

\section{CONSIDERAÇÕES FINAIS}

Esse artigo analisou as atitudes de alunos matriculados em uma disciplina a distância em uma instituição de ensino superior do Sul do Brasil. Em geral, as atitudes dos alunos foram predominantemente negativas com relação à maioria das categorias investigadas. Em especial, foram negativas as atitudes dos alunos quanto às categorias desempenho, flexibilidade e conveniência, preparação para a educação a distância, material didático e dinâmica de grupo na lista de discussão. Nessas categorias não houve concordância quanto a nenhuma assertiva que indicava as potencialidades positivas da educação a distância.

Foram concebidas algumas interpretações para compreender as razões das atitudes negativas, especialmente porque os resultados, em diferentes momentos, apresentaram-se em dissonância com os verificados em outros estudos semelhantes (Havice, 1999; Valenta \& cols., 2001). Tomar conhecimento da modalidade educacional da disciplina apenas no primeiro dia de aula pode ter suscitado um sentimento de quebra de contrato psicológico, influenciando no desenvolvimento de uma atitude negativa com relação à disciplina.

Soma-se a isso o esquema representativo tradicional da situação de ensino/aprendizagem, que pode gerar sentimentos de apreensão e ceticismo quando os alunos se deparam com uma configuração que exclui a característica mais marcante da representação tradicional: a presença do professor e do aluno no mesmo espaço e tempo. Nesse contexto, os alunos podem ter compreendido a educação a distância como mero meio de armazenamento e disseminação de conteúdos, e não como modelo de ensino/aprendizagem que utiliza tecnologias para mediar parte desse processo. $\mathrm{Na}$ percepção dos alunos, o não-cumprimento das obrigações da instituição de prover uma situação de ensino/aprendizagem coerente com o esquema representativo tradicional afeta negativamente a percepção global do aluno de que a instituição pode não estar comprometida com ele.

Este estudo constatou que o impacto positivo da educação a distância esperado pela instituição não ocorreu em toda a sua extensão. Estudos têm demonstrado que as atitudes com relação a inovações como a virtualização de disciplinas influem grandemente na sua aceitação (ou rejeição). No caso da instituição que ofereceu a disciplina exclusivamente a distância, a análise das atitudes dos alunos não foi realizada antes dessa oferta, da mesma forma que foram desconsiderados os estágios necessários para a decisão sobre uma inovação: conhecimento, persuasão, decisão, implementação e confirmação (Rogers, 1994).

Embora os resultados deste estudo não possam ser generalizados para toda a instituição, ou para outras instituições de ensino superior, esta pesquisa suscita uma reflexão sobre a necessidade de maior planejamento para a oferta de disciplinas a distância. O planejamento se configura na principal etapa para assegurar as condições necessárias para uma adoção exitosa de programas de educação a distância (Levy, 2003; Rumble, 2000). Essa etapa envolve uma análise sistêmica dos seguintes aspectos: a) visão da instituição, b) currículo, c) capacitação de professores e equipes de apoio, d) serviços aos alunos, e) capacitação e suporte aos alunos e f) propriedade intelectual e direitos autorais (Levy, 2003). Importante nesse processo é considerar a virtualização educacional como uma prática educacional inovadora, que gera novos desafios para a situação de ensino/aprendizagem, para os quais a instituição educacional deve estar adequadamente preparada.

Por fim, os resultados do estudo refletem tendências iniciais e poderão ser mais detalhadamente investigados em estudos futuros. Neste sentido, o presente estudo se posiciona, de acordo com Snow e Thomas (1994), com o foco na identificação de insumos para a construção de teorias, e não em sua testagem per se. 


\section{REFERÊNCIAS}

Ajzen, I. (2001). Nature and operations of attitudes. Annual Reviews Psychology, 52, 27-58.

Akerling, G. \& Trevitt, C. (1999). Enhancing self-directed learning through educational technology: When students resist the change. Innovations in Education and Training International, 36(2), 96-105.

Alexander, S. (2001). E-learning developments and experiences. Education + Training, 43(4/5), 240-248.

Aretio, L. G. (2001). La Educación a Distancia. De la teoría a la práctica. Barcelona: Editorial Ariel.

Ascough, R. S. (2002). Designing for online distance education: putting pedagogy before technology. Teaching Theology and Religion, 5(1), 17-29.

Baer, W. S. (2000). Competition and collaboration in online distance learning. Information, Communication and Society, 3(4), 457-473.

Bargh, J. A. \& Chartrand, T. L. (1999). The unbearable automaticity of being. American Psychologist, 54, 462-479.

Bennet, R. \& Kottasz, R. (2001). Marketing undergraduates' attitudes towards query-based instructional machines as possible learning medium. British Journal of Educational Technology, 32(4), 471-482.

Berge, Z. L. (2002). Obstacles do distance training and education in corporate organizations. Journal of Workplace Learning, 14(5), 182-189.

Commonwealth of Learning (2003). Virtual university for small states of the commonwealth. Retrieved July, 2004 from http://www.col.org

Evans, C., Gibbons, N. J., Shah, K. \& Griffin, D. K. (2004). Virtual learning in the biological sciences: Pitfalls of simply 'putting notes on the web'. Computers \& Education, 43, 49-61.

Evans, T. (1994). Understanding learners in open and distance education. Open and Distance Education Series. London: Kogan Page.

Fiske, S. T. \& Taylor, S. E. (1984). Social Cognition. New York: Random House.

Fulford, C. P. \& Zhang, S. (1993). Perceptions of interaction: The critical predictor in distance education. American Journal of Distance Education, 7(3), 8-21.

Griffiths, L., Ashoweth, J., Ward, H. \& Mardsen, P. (1999). Learning on-line: Student behaviour in a virtual campus. Virtual University Journal, 4, 76-85. Retrieved April 24, 2005 from http://openhouse.org.uk/virtual-university-press/.

Gunawardena, C. N. \& Zittle, F. J. (1997). Social presence as a predictor of satisfaction within a computer-mediating conferencing environment. American Journal of Distance Education, 11(3), 8-26.

Havice, W. L. (1999). College students' attitudes toward oral lectures and integrated media presentations. The Journal of Technology Studies, 25(1), 51-55.

Hong, K. S., Lai, K. W. \& Holton, D. (2003). Student's satisfaction and perceived learning with a web-based course. Educational Technology \& Society, 6(1), 116-124.
Inman, E., Kerwin, M. \& Mayes, L. (1999). Instructor and student attitudes toward distance learning. Community College Journal of Research and Practice, 23, 581-591.

International Standards Organisation (1999). ISO 9241- Part 10 to 17. (Software aspects).

Lavine, H., Thomsen, C. J., Zanna, M. P. \& Borgida, E. (1998). The primacy of affect in the determination of attitudes and behavior: The moderating role of affective-cognitive ambivalence. Journal of Experimental Social Psychology, 34, 398-421.

Layton, J. R. (1999). No significant difference phenomenon (book review). Educational Technology \& Society, 2(3), 5-9.

Levy, S. (2003). Six factors to consider when planning online distance learning programs in higher education. Online Journal of Distance Learning Administration, 6(1), Retrieved April 24, 2005 from http://www.westga.edu/ distance/ojdla/spring61/levy61.htm.

Long, P. D., Tricker, T., Rangecroft, M. \& Gilroy, P. (2000). Satisfaction with distance education: Evaluation of a service template. Total Quality Management, 11(4-6), 530-536.

Lowe, C. \& Gunawardena, C. (2005). A model and taxonomy for designing evaluation and research in distance education. Retrieved January 22, 2005 from http://www.fernunihagen.de/ICDE/final/s_lists/abstract/u2c01666.htm

Martins, C. B. M. J., Steil, A. V. \& Todesco, J. L. (2004). Factors influencing the adoption of the Internet as a teaching tool at foreign language schools. Computers \& Education, 42(4), 353-374.

McGorry, S. Y. (2002). Online, but on target? Internet-based MBA courses. A case study. Internet and Higher Education, 5, 167-175.

McGreal, R. (1994). Comparison of the attitudes of learners taking audio graphic teleconferencing courses in secondary schools in northern Ontario. Interpersonal Computing and Technology, 2(4), 11-23.

Ministério da Educação. (2003). Censo da Educação Superior 2003. Resumo Técnico. Instituto Nacional de Estudos e Pesquisas Educacionais Anísio Teixeira. Retrieved April 24, 2005 from http://www.inep.gov.br/superior/censosuperior/default.asp.

Morrison, E. W. \& Robinson, S. L. (1997). When employees feel betrayed: A model of how psychological contract violation develops. Academy of Management Review, 22(1), 226-256.

Ocker, R. J. (2001). Collaborative learning environments: Exploring students' attitudes and satisfaction in face-to-face and asynchronous computer conferencing settings. Journal of Interactive Learning Research, 12(4), 427-448.

Ponzurick, T., France, K. R. \& Logar, C. M. (2000). Delivering graduate marketing education: An analysis of face-to-face versus distance education. Journal of Marketing Education, 22(3), 180-187.

Rogers, E. M. (1994, $4^{\text {a }}$ ed.). Diffusion of innovations. New York: The Free Press.

Rumble, G. (2000). The globalization of open and flexible learning: Considerations for planners and managers. Online Journal of Distance Administration 3(3). Retrieved April 24, 2005 from http://www.westga.edu/ distance/ojdla/fall33/rumble33.html.

Schein, E. (1965). Organizational psychology. Englewood Cliffs: Prentice Hall. 
Snow, C. \& Thomas, J. (1994). Field research methods in strategic management:

contributions to theory building and testing. Journal of Management Studies, 31(4), 457-480.

U.S. Department of Education (2004). The condition of education. National Center for Education Statistics - NCES, June 2004. Retrieved April 24, 2005 from http://www.nces.ed.gov/pubs2004/2004077.pdf.

Valenta, A., Therriault, D., Dieter, M. \& Mrtek, R. (2001). Identifying student attitudes and learning styles in distance education. Journal of Asynchronous Learning Networks, 5(2), 111-127.
Waugh, R. F. (2002). Creating a scale to measure motivation to achieve academically: linking attitude and behaviours using Rasch measurement. British Journal of Educational Psychology, 72, 65-86.

Weller, M. J. (2000). Creating a large-scale, third generation distance education course. Open Learning, 15(3), 243-252.

Wood, W. (2000). Attitude change: persuasion and social influence. Annual Reviews Psychology, 51, 539-570.

Recebido em 08/11/2004

Aceito em 30/05/2005

Endereço para correspondência: Andrea Valéria Steil, Rodovia SC-401, Km 1, Parqtec Alfa, Bairro João Paulo, CEP 88030000, Florianópolis-SC. E-mail: andrea@ vias.org.br 